\title{
Uma história ambiental da modernização da agricultura: 0 norte do Rio Grande do Sul
}

Una historia ambiental de la modernización de la agricultura: el norte de Rio Grande do Sul A environmental history of agricultural modernization: the north of Rio Grande do Sul

Marcos Gerhardt ${ }^{*}$

\section{Resumo}

Este artigo descreve e analisa as principais mudanças socioambientais provocadas pela modernização da agricultura no norte do estado do Rio Grande do Sul, em um curto período de tempo, na década de 1970. Utiliza-se como fonte de pesquisa um jornal editado pela Cooperativa Tritícola de Passo Fundo, representando os interesses e projetos de diversas outras cooperativas de produção de municípios próximos. Analisa-se, portanto, as particularidades locais e regionais de um processo de modernização que se desenvolveu em escala nacional e internacional, conhecida como Revolução Verde. Conclui-se, então, que as mudanças foram intensas e profundas, mas não isentas de críticas e da proposição de alternativas.

Palavras-chave: História rural. Revolução Verde. Passo Fundo.
O foco deste artigo incide nas transformações geradas pela modernização da agricultura no norte do Rio Grande do Sul. Esse espaço, primitivamente coberto pelas florestas Estacional Decidual e Ombrófila Mista (VELOSO; RANGEL FILHO; LIMA, 1991), entremeado com campos que formavam mosaicos (BERNARDES, 1997), foi território de populações Kaingang (GOLIN, 2006), lugar de uma ativa economia ervateira extrativista no século XIX (LINHARES, 1969; GERHARDT, 2013), campo utilizado para a pecuária extensiva, terra privatizada no contexto da Lei de Terras de 1850 (ZARTH, 1997; MACHADO, 2012) bem como ambiente desmatado para alimentar o comércio madeireiro e para viabilizar os projetos de colo-

Doutor em História pela Universidade Federal de
Santa Catarina. Pesquisador e professor na gradua-
ção em História e no Programa de Pós-Graduação em
História da Universidade de Passo Fundo. E-mail:
marcos@gerhardt.pro.br

Recebido em 02/03/2016 - Aprovado em 28/03/2016 http://dx.doi.org/10.5335/hdtv.16n.1.6264 
nização e de repovoamento por imigrantes descendentes de europeus nos séculos XIX e XX (ROCHE, 1969; WENTZ, 2004; ZARTH, 2012; TEDESCO; NEUMANN, 2013). Foi, também, lugar de profundas mudanças socioambientais nas décadas de 1960 e 1970. Mas, especificamente, em meados da década de 1970, quais foram essas alterações? Essa é a pergunta que o artigo objetiva responder, como parte de uma investigação maior.

Emprega-se a abordagem da história ambiental, pois se quer discutir a relação humana com o ambiente no contexto de produção agropecuária e por sua capacidade de "ampliar a análise historiográfica e trazer novas perspectivas para o estudo de antigos problemas historiográficos" (PÁDUA, 2010, p. 94).

A principal fonte de pesquisa foi o Agro-Jornal, um periódico editado e distribuído pela Cooperativa Tritícola de Passo Fundo Ltda., de 1974 a 1980, hoje disponível no Arquivo Histórico Regional da Universidade de Passo Fundo, era sucessor do Cooperativa-Jornal, periódico original. Era distribuído, em 1976, nas cooperativas tritícolas de Passo Fundo, Getúlio Vargas, Erechim, Charrua, Marau, Sananduva, Vacaria e Lagoa Vermelha e em outras instituições, como o Sindicato dos Trabalhadores Rurais e a Faculdade de Agronomia da Universidade de Passo Fundo (AGRO-JORNAL, set. 1976, p. 1). Isso confere ao artigo uma característica marcante: exprimir a visão sobre a modernização da agricultura dos autores do periódico, dos diretores da cooperativa e dos empresários ligados à indústria e ao comércio de equipamentos e insumos agrícolas. Ao historiador cabe a interpretação desses testemunhos e o esforço para compreender e explicar a história do período.
A opção por essa fonte de pesquisa também estabelece os parâmetros para o recorte temporal da análise. Embora a modernização tenha se desenvolvido no norte do Rio Grande do Sul durante um período de tempo maior, decidiu-se por olhar mais atentamente para o curto intervalo entre 1974 e 1976, quando o processo se intensificou.

\section{A modernização da agricultura e da pecuária}

Mecanização, modernização ou industrialização da agricultura são termos usados para definir o amplo conjunto de mudanças que reconfigurou as formas de produção agrícola e pecuária, de organização do espaço agrário, de trabalho, de sociabilidade humana, de alimentação e de utilização dos bens ambientais. Foi definida por Argemiro J. Brum como uma modernização conservadora, que teve por objetivo "o aumento da produção e da produtividade, isto é, a utilização de métodos, técnicas, equipamentos e insumos modernos, sem que seja tocada ou grandemente alterada a estrutura agrária" (1985, p. 83). A modernização ligou-se à Revolução Verde, um programa encabeçado pelo grupo econômico Rockfeller, que:

[...] tinha como objetivo explícito contribuir para o aumento da produção e da produtividade agrícola no mundo, através do desenvolvimento de experiências no campo da genética vegetal para a criação e multiplicação de sementes adequadas às condições dos diferentes solos e climas e resistentes às doenças e pragas, bem como da descoberta e aplicação de técnicas agrícolas ou tratos culturais mais modernos e eficientes (BRUM, 1985, p. 59). 
De acordo com o sociólogo Antônio Andrioli, a Revolução Verde baseava-se em três elementos interligados:

1) a mecanização, através da produção de tratores, colheitadeiras e equipamentos; 2 ) a aplicação de adubo químico, pesticidas e medicamentos para a criação de animais; 3) o progresso na biologia, através do desenvolvimento de sementes híbridas e novas raças de animais com potencial produtivo superior (ANDRIOLI, 2008, p. 103).

Conforme Clive Ponting, "a introdução de variedades altamente produtivas de trigo e arroz", respectivamente, no México e nas Filipinas, na década de 1940, aumentou a produção agrícola, de modo que nos anos 1960 a Revolução Verde "era alardeada como a solução para o problema da falta de alimento suficiente para sustentar a população crescente do Terceiro Mundo" (1995, p. 406). O resultado da adoção das novas variedades em várias partes do planeta foi, contudo, desastroso para uma parte dos agricultores, pois as culturas dependiam "de grandes quantidades de fertilizantes e também de grandes quantidades de pesticidas". A Revolução Verde acentuou, assim, "as diferenças sociais existentes e a tendência acelerada em direção à mecanização e às propriedades maiores" (1995, p. 406).

Esse processo, pensado e desenvolvido internacionalmente, teve uma dimensão regional, ou seja, a modernização foi efetivada no espaço local, nos lugares de produção agropecuária, em Passo Fundo e em outros territórios do norte do estado. A região definida para este estudo corresponde, aproximadamente, ao que foi o território do grande município de Passo Fundo em 1890 (FELIZARDO, 1981), do qual se desmem- braram diversos municípios, como Carazinho, Getúlio Vargas, Erechim, Tapejara, Marau e Sertão, emancipados até a década de 1960. Esse recorte combina critérios fitogeográficos, socioambientais e administrativos: a presença primitiva da floresta intercalada com campos, a ocupação humana para a agricultura cabocla e colonial e a centralização administrativa em Passo Fundo, local de instalação de diversas empresas ou de seus representantes, que foram centrais para viabilizar a modernização agrícola. O olhar volta-se, então, para o regional e para o específico, sem perder a conexão com o geral.

\section{As máquinas anunciadas, os insumos e os representantes comerciais}

Parte considerável das páginas do Agro-Jornal, no período analisado, foi ocupada com propagandas de máquinas agrícolas, geralmente compostas de figuras ilustrativas, da descrição de suas características e qualidades, do nome ou marca do fabricante e de seu distribuidor ou fornecedor regional.

Anúncios dos pulverizadores Hatsuta e Jacto, dos tratores Valmet, CBT e Massey Ferguson, de caminhões FNM, de plantadeiras das marcas Semeato e Egan, de colheitadeiras automotrizes Vassalli, Claas e Ideal, todos apresentados como inovações produtivas, dividiram espaço com ofertas de trilhadeiras, motores estacionários de pouca potência e plantadeiras de tração animal "para o pequeno produtor" (COOPERATIVA-JORNAL, dez. 1974, p. 19). As propagandas estampavam a substituição tecnológica em curso, apresentando simultaneamente as novas tecnologias e aquelas 
que, mesmo sendo menos produtivas, ainda sobreviviam ou se destinavam ao agricultor menos capitalizado. Era o tempo da mudança, quando o velho e o novo conviviam nas páginas do jornal.

A Imasa, de Ijuí, e a Industrial Busse Ltda. (IBL), de Cerro Largo, ambas no Rio Grande do Sul, anunciavam grades de discos e arados subsoladores, tidos como importantes implementos acopláveis ao trator, ícones da mecanização agrícola e do plantio convencional. Logo, no intervalo de dois anos, começaram a figurar no periódico analisado, os anúncios de semeadeiras para o plantio direto com cobertura de palha sobre o solo. O anunciante da semeadeira-adubadeira Rotacaster, com dois modelos disponíveis, a RT60 "para quem tem trator pequeno" e a RT-80 "para quem tem trator grande", apresentou o plantio direto como "um no[vo] conceito em mecanização agrícola" (AGRO-JORNAL, fev. 1976, p. 12). Ainda em 1976, anunciou-se para venda a "Máquina Imasa de plantio direto", que oferecia "Separação perfeita de adubo e semente, profundidade regulável e uniforme, acompanhando a ondulação do terreno, com excelente cobertura e compactação [...]" (AGRO-JORNAL, fev. 1976, p. 17). Esse sistema de manejo do solo, que evitava a aração prévia, foi desenvolvido no Paraná, no Instituto de Pesquisa de Experimentação Agropecuária Meridional, a partir de 1971 (FEDERAÇÃO BRASILEIRA DE PLANTIO DIRETO E IRRIGAÇÃO, [ca. 2013]).

Alguns clientes, que contribuíram com testemunho nos anúncios, não eram pequenos agricultores, e cultivavam 290, 540 ou 600 hectares de soja, para citar alguns casos (AGRO-JORNAL, jan. 1976, p. 3).
$\mathrm{O}$ grande número de anúncios de produtos agrícolas nas páginas do Agro-Jornal permite que se constate a expressiva quantidade de empresas fornecedoras de máquinas e insumos. Elas representavam e distribuíam grandes marcas de fabricantes nacionais e internacionais. O Comércio de Máquinas Passofundense Ltda. (Comapa) fornecia produtos da Shell Química, que podiam ser encontrados "em grande sortimento na Cooperativa Tritícola de Passo Fundo" (COOPERATIVA-JORNAL, jan. 1975, p. 3).

O jornal estampou ainda anúncios das empresas Cocito Comércio e Representações, Comercial Marekis, Darcelio Britto \& Cia. Ltda., Comercial Agropecuária Lavrador, Lojas Guaraé, Lojas BM, Gaúcha Automotor, Comércio e Representações Ponteio, Comercial Santo Izidoro, Cardozo Marques S.A., Oliquerque, Seagro, Auto Agrícola Passo Fundo, Comercial de Produtos Agrícolas Barbosa Ltda., Crema Comércio e Representações de Máquinas Agrícolas e Caetano Branco S.A. A lista serve para evidenciar o número expressivo de empresas que atuavam na região estudada. Algumas delas obtiveram considerável poder econômico e prestígio social.

A inauguração do depósito de produtos da Shell em Passo Fundo, em 1974, ligado à empresa Comapa, foi apresentada pelo jornal como portadora de "Um nobre objetivo [...], uma grande conquista para a cidade e para a própria região", e contou com a presença, entre outras personalidades, do bispo de Passo Fundo Dom Claudio Colling. Para a autoridade religiosa, que abençoou o depósito, o local atendia à "necessidade de um sempre crescente amparo dos que procuram 
na terra o alimento para o mundo faminto" (COOPERATIVA-JORNAL, dez. 1974, p. 12).

Em 1975, veio de Londres para Passo Fundo o diretor da Divisão de Químicos Agrícolas do Grupo Shell, John Smith, acompanhado do diretor e de gerentes da empresa no Brasil. Os visitantes foram recebidos pelo proprietário do Comapa e por dirigentes da Cooperativa Tritícola, o grupo visitou as instalações e tratou da "possibilidade do lançamento de produtos mais sofisticados que venham a fazer com que uma mesma área atualmente cultivada a produção se torne muito maior" (COOPERATIVA-JORNAL, fev. 1975, p. 10).

Ainda em 1975, o jornal apresentou matéria sobre a doação de fundos, obtidos pelo Comapa com a Shell, para a Faculdade de Agronomia da Universidade de Passo Fundo, para experimentos com seus produtos. A seguir, o periódico noticiou a doação, para as "atividades práticas" da mesma instituição de ensino, de 150 toneladas de calcário e de 25 toneladas de adubo, obtidas pelo Comapa com a Adubos Pampa, outra representada. Obteve-se ainda adubo para fertilizar todas as árvores plantadas pela prefeitura na Praça Antonino Xavier e Oliveira, e foi contratado um vigia para evitar que elas fossem arrancadas (COOPERATIVA-JORNAL, set. 1974 , p. 8; ago. 1975 , p. 20).

\section{Aintrodução da soja}

O trigo era o principal cultivo agrícola de inverno em Passo Fundo e em vários outros municípios próximos, na década de 1970. Abundantes eram os anúncios de fungicidas para o trigo. A soja (Glycine max), cul- tura de verão, apareceu com crescente importância no jornal tomado como fonte para a pesquisa, e foram publicados textos que orientavam sobre "a soja e suas pragas", explicando as qualidades alimentares do grão, comentando as remotas origens da planta, noticiando a criação de lavouras demonstrativas, elogiando a "extraordinária soja", o "grão milagroso" e outros mais (COOPERATIVA-JORNAL, nov. 1974; ago. 1975; AGRO-JORNAL, nov. 1975; jul. 1976, p. 5-6).

Em 1974, a Cooperativa de Passo Fundo iniciou a instalação de uma grande unidade de beneficiamento de soja para extrair óleo vegetal, aumentando a capacidade de recebimento de grãos. Iniciou-se, no mesmo ano, a fabricação da ração e do concentrado Trisoja, para suínos e bovinos, "suplementos com minerais, vitaminas, aminoácidos, antibióticos e fatores de crescimento" (COOPERATIVA-JORNAL, ago. 1974; dez. 1974, p. 3). A produção dessa ração correspondeu a uma das faces da modernização, aquela que se voltou para a pecuária, aproximando a criação de bovinos, aves e suínos da lógica industrial.

Conforme dados da Cooperativa Tritícola de Passo Fundo, a empresa recebeu 231.893 sacos de soja em 1968, que passaram para 2.300.000 sacos em 1974, um crescimento espantoso que, possivelmente, aconteceu devido ao aumento da produtividade, pelo desmatamento e incorporação de novas áreas agrícolas e em detrimento do cultivo do milho (COOPERATIVA-JORNAL, mar. 1975), antes também usado para alimentar os animais criados.

Em 1976, a Federação das Cooperativas de Trigo do Rio Grande do Sul previu a 
maior safra de soja no estado até então, cerca de 5milhões de toneladas (AGRO-JORNAL, fev. 1976). A Associação Sulina de Crédito e Assistência Rural (Ascar) e sua extensão rural tiveram um papel importante na introdução da soja e na modernização, pois acompanhavam muitos agricultores durante a implantação e na aprendizagem para uso do "pacote tecnológico". O programa denominava-se Crédito Rural Educativo, e era financiado, principalmente, pelo Banco do Brasil (AGRO-JORNAL, mar. 1976, p. 19; abr. 1976; jun. 1976).

\section{0s defensivos na agricultura}

Outra parte expressiva do Agro-Jornal, no período estudado, continha anúncios de "defensivos" agrícolas, alguns ocupando página inteira. A palavra expressa a posição de defesa contra uma agressão, era o discurso da necessidade de defender os cultivos do ataque das pragas. Os venenos oferecidos fungicidas, inseticidas e herbicidas - faziam parte do pacote tecnológico para uma agricultura mais produtiva, e eram fabricados por indústrias químicas como Shell, Pfizer, Hoechst, Elanco, Bayer.

Shellvin, Fostion, Endrin, Endrex, Azodrin, Toxaparathane, Endolix, Dimethane, Dikofag (2,4 D), Dimetoato, Parathion, Folidol, Malathion, Thiodan e Thionexfor formavam uma lista de inseticidas, geralmente anunciados com seus nomes comerciais. Para controlar insetos que se alimentavam da soja, recomendou-se aplicar um composto de Folidol e diclorodifeniltricloroetano ou DDT (COOPERATIVA-JORNAL, dez. 1974, p. 21). O primeiro produto tem como prin- cípio ativo o parathionmethyl, um organofosforado, hoje considerado extremamente tóxico, ou seja, da Classe I, em uma escala que vai até IV, conforme a Agência Nacional de Vigilância Sanitária (Anvisa) (2001). O segundo composto, o DDT, fora denunciado como perigoso para o ambiente e para as pessoas na década de 1960 (CARSON, 1964). A Agência de Proteção Ambiental norte-americana considera-o muito persistente no ambiente, cumulativo no tecido adiposo de animais e humanos e com capacidade para se deslocar por longas distâncias na atmosfera. Nos Estados Unidos, o DDT foi proibido para uso na agricultura na década de 1970 (UNITED STATES ENVIRONMENTAL PROTECTION AGENCY, [ca. 2015]), no Brasil, entretanto, somente no início deste século (BRASIL, 2009).

Recomendações agronômicas semelhantes às do Cooperativa-Jornal foram encontradas em edições do final da década de 1960 do jornal Correio Serrano, que circulou no noroeste do Rio Grande do Sul (GERHARDT; NEDEL, 2009). Em Passo Fundo, um dos representantes comerciais transcreveu alguns argumentos da indústria química: “DEFENSIVOS - há uma solução: preferir produtos de baixa toxicidade - COMO OS NOSSOS - seguindo sempre as indicações técnicas". O argumento estava contido em um balão de diálogo, representando a voz do cientista da ilustração. Oferecia-se a seguir, para venda, entre outros produtos, o Thionexfor 25, um "inseticida especialmente indicado para plantações de algodão e soja, não é tóxico para culturas, e pode ser misturado a fungicidas" (AGRO-JORNAL, maio 1976, p. 7, grifo do autor). Esse inse- 
ticida tinha como princípio ativo o endossulfan, um organoclorado que não é tóxico para o vegetal soja, como afirmou a propaganda, mas que é classificado, hoje, como altamente perigoso ao meio ambiente (Classe I), altamente persistente no meio ambiente, altamente bioconcentrável em peixes e altamente tóxico para minhocas e organismos aquáticos (MAKHTESHIM, 2015; ANVISA, 2009). Para humanos, é um "composto neurotóxico com fortes evidências de ação desreguladora endócrina, exibindo efeitos de imunotoxicidade [...] e efeitos sobre o sistema reprodutivo" (ANVISA, 2009, p. 38). Sua proibição, no Brasil, aconteceu somente em 2010 (BRASIL, 2010).

Os herbicidas também figuraram nos anúncios: "Daqui a cinco anos você estará pobre", argumentou o fabricante da Rotacaster, a semeadeira de plantio direto que prometia controlar a erosão e a compactação do solo provocadas pelo plantio convencional. Nas mesmas páginas, estavam argumentos técnicos a favor da "Nova técnica revolucionária de produção" e também um anúncio de Gramoxone, nome comercial do herbicida baseado em paraquat (AGRO-JORNAL, fev. 1976, p. 12-13), que não é seletivo, ou seja, mata plantas daninhas e cultivadas, de folhas estreitas e largas. Era utilizado para formar a camada de palha seca que cobria o solo no plantio direto. Por um lado, esse sistema trouxe vantagens, como a redução do uso de máquinas, menor perda de tempo, solo e nutrientes, conservação da umidade e da estrutura do solo. Por outro, ampliou o uso do paraquat, considerado extremamente tóxico (Classe I), muito perigoso para o meio ambiente, altamente persistente, corrosivo e irritante para os olhos e para a pele e sem antídoto para tratar as intoxicações (SYNGENTA, 2015). A Anvisa está reavaliando, atualmente, a permissão de uso do paraquat na agricultura. A base legal para regular a produção e o uso de agrotóxicos no país foi estabelecida mais claramente a partir do final da década de 1980 (BRASIL, 1989, 2000, 2002).

"Continue arando e gradeando sua terra antes de plantar soja e trigo [...]", publicou a Companhia Imperial de Indústrias Químicas do Brasil, da transnacional britânica Imperial Chemical Industries (ICI), fundada em 1926, "[...] continue. Depois, não venha reclamar da erosão. Plantio direto com Gramoxone é a solução". Dos demais argumentos, acompanhados por uma imagem de solo erodido, destaca-se: “É só querer. Nada mais. O resto deixe por conta dos agrônomos da Imperial [...]". No final, o anúncio identificou dois "Centros de Pesquisa e Desenvolvimento sobre Plantio Direto", um em Rolândia, Paraná, onde o sistema foi introduzido originalmente, e outro em Passo Fundo (AGRO-JORNAL, mar. 1976, p. 2).

As preocupações com a conservação do solo eram legítimas e diversos grupos promoveram as práticas conservacionistas na época. Contudo, como esperado, os anúncios apresentavam somente os benefícios e as facilidades do novo sistema. Não houve qualquer referência aos riscos para a saúde humana e de contaminação ambiental que o uso do paraquat podia trazer. A segurança e a garantia técnica aparecem também como argumentos nos textos comerciais de outros representantes. Um deles publicou: “[...] servindo a lavoura. Assistência técnica 
e garantia do que vende. Lucro certo e garantido na agricultura é com a [...]. Uma tradição de qualidade" (AGRO-JORNAL, ago. 1976, p. 2). Ainda em 1976, o Agro-Jornal (set. 1976, p. 19) noticiou uma reunião técnica de engenheiros-agrônomos da ICI e representantes da Secretaria da Agricultura do estado com agricultores, para tratar das vantagens do plantio direto.

Outros herbicidas foram anunciados de modo recorrente nas páginas do Agro-Jornal no período estudado. $\mathrm{O}$ "mata-mato Treflan", da indústria Elanco, era apresentado como o "Produto que nunca falhou, assistência técnica que não falha e experiência". Os argumentos prosseguiam: "Quando o mata-mato entra em ação, não há mato que atrapalhe, nem agricultor que precise fazer força para manter a colheita no limpo" (AGRO-JORNAL, out. 1975, p. 24). Sua eficiência, a assistência disponível e a redução do trabalho proporcionada, em comparação à agricultura que utilizava ferramentas manuais, eram ressaltadas. Eventualmente, pôde-se encontrar anúncio do Basagran, herbicida da BASF, apresentado como "novo e revolucionário" em palestra dos técnicos da indústria aos agricultores, técnicos e agrônomos da Embrapa e Ascar, acadêmicos de agronomia e diretores da cooperativa (AGRO-JORNAL, ago. 1975, p. 20).

Esses dois produtos têm como princípios ativos a trifluralina e a bentazona, respectivamente, que entram nas categorias altamente tóxico (Classe II) e extremamente tóxico (Classe I). Ambos são altamente persistentes no meio ambiente e a bentazona é altamente móvel, podendo atingir águas subterrâneas. Esses compostos químicos são perigosos, pois seu efeito não se restringe às plantas, visto que causa danos à saúde de humanos e mamíferos em geral, bem como a peixes e outros organismos aquáticos (NORTOX, 2014; BASF, 2013).

O Agro-Jornal publicou diversos textos técnicos sobre as pragas e plantas invasoras dos cultivos de trigo e soja. Em um deles, um engenheiro-agrônomo apresentou ao leitor, isto é, ao agricultor, uma lista de pragas, a correspondente indicação do inseticida a ser usado e defendeu um critério de escolha: que seja "barato, não poluente e que possua uma eficiência comprovada". Em sua lista estavam Sevin, Endrin e Canfeno Clorado para matar lagartas da soja (COOPERATIVA-JORNAL, nov. 1974, p. 7), que certamente eram eficientes, talvez baratos, mas não podiam ser considerados não poluentes. O Canfeno Clorado, ou toxafeno, é tóxico para espécies aquáticas, para algumas espécies terrestres, e mostrou-se um agente cancerígeno em testes de laboratório. Em 1975, era o inseticida mais usado nos EUA. Atualmente, está entre as doze substâncias classificadas como contaminantes orgânicos persistentes pela Conferência de Estocolmo (ESPAÑA, 2004).

Jó Klanovicz empregou o conceito de húbris agronômica para estudar a história de monocultivos no Brasil, definindo como "a arrogância ou crença na certeza das estratégias, intervenções e racionalizações desse campo do conhecimento sobre a produção de alimentos" (2012, p. 134), corresponde às práticas discursivas, institucionais e cotidianas utilizadas pela ciência e a tecnologia para produzir significados. Além da expectativa de maior produtividade e de ganhos 
econômicos, a autoridade técnica e científica dos engenheiros-agrônomos e técnicos agrícolas foi decisiva para que os agricultores adotassem o pacote tecnológico da modernização e abandonassem as práticas anteriores, ligadas à agricultura colonial e cabocla, vistas como atrasadas. Parte dos agrônomos tornou-se a ponte entre as grandes empresas e os agricultores.

A agricultura modernizada visou intensificar ainda mais a transformação do ecossistema natural, que é "um subgrupo da economia global da natureza - um sistema local ou regional de plantas e animais que trabalham em conjunto para criar os meios de sobrevivência" em um sistema agroecológico, que é "um ecossistema reorganizado para propósitos agrícolas - um ecossistema domesticado", ou seja, "é um rearranjo", mas "não uma anulação dos processos naturais" (WORSTER, 2002-2003, p. 29-30). Podemos entender a modernização com uma complexa combinação de fatores biofísicos (solo, clima, insetos, etc.), sociais e culturais sempre presentes, evitando a dualidade natureza e cultura, ou técnica versus natureza (PÁDUA, 2010), presente em diversos textos do jornal analisado.

Em 1976, a Companhia Riograndense de Adubos (CRA) promoveu um encontro, ofereceu um churrasco e homenageou o engenheiro-agrônomo "que, com seus conhecimentos técnicos e práticos, desbravou a mata e plantou no Rio Grande uma civilização". A seguir, foi apresentado um novo produto, o hiperfosfato, e apregoada a eficiência do Basagran, pois quem representava a CRA também comercializava produtos BASF em Passo Fundo (AGRO-JORNAL, out. 1976, p. 25). Antes, na comemoração do Dia do Agrônomo de 1975, a Manah publicou mensagem "à nobre e dignificante classe dos engenheiros agrônomos, 'os médicos da terra', pela sua marcante presença no desenvolvimento brasileiro" (AGRO-JORNAL, out. 1975, p. 14). A Elanco e a Monsanto também mantinham contato com os engenheiros-agrônomos (AGRO-JORNAL, ago. 1976; out. 1976).

Em 1974, o governo do Rio Grande do Sul reuniu dados sobre o uso de defensivos na safra de soja de 1973-1974. É difícil saber se eles são confiáveis, mas permitem compor um quadro assustador: no período foram usados, no estado, cerca de $10 \mathrm{mil}$ toneladas de defensivos em pó, e 1.700.000 litros de veneno líquido. Houve, no mesmo período, 652 casos de intoxicação de agricultores, dos quais 428 exigiram hospitalização e seis resultaram em óbito. A morte de animais criados também foi informada no jornal: 549 bovinos, 121 ovinos e 235 suínos, bem como peixes e outras espécies da fauna local (COOPERATIVA-JORNAL, set. 1974, p. 11). Estudos de história ambiental, feitos sob a coordenação de Eunice Sueli Nodari em Santa Catarina, revelaram números igualmente preocupantes de intoxicações por agrotóxicos durante a modernização.

Cerca de um ano e meio depois, em texto sem identificação de autor, rebateram-se as declarações do titular "da Pasta da Agricultura feitas perante as comissões da Saúde e de Agricultura da Assembléia Legislativa em torno do problema dos defensivos agrícolas, e que podem tornar-se nocivos à saúde da população e causar danos à fauna e à flora". Argumentou-se que, em 
Passo Fundo e em municípios próximos, foram dois anos sem intoxicação por venenos agrícolas, e que: "Em síntese, os defensivos agrícolas são neutros em si, seus efeitos negativos e positivos dependem da cautela e da maneira como eles são utilizados" (AGRO-JORNAL, mar. 1976, p. 22, grifo nosso).

Em outro texto publicado sem identificação de autoria, o argumento foi retomado:

OS ÍNDICES DE CRESCIMENTO da produtividade agrícola encontram-se relacionados com a utilização de fungicidas e defensivos agrícolas [...]. Não é porque possam ser prejudiciais à fauna e à flora e à própria saúde do homem, que eles devem ser proscritos, pois sua presença é neutra para todos, tornando-se no entanto, benéfica ou maléfica consoante a sua adequada utilização (AGRO-JORNAL, ago. 1976, p. 13, grifo do autor).

Dos dados apresentados, destaca-se: “[...] o meio ambiente estadual recebeu em 75 perto de 30 mil toneladas de defensivos, o que corresponde a uma concentração por hectare [agricultável] bastante expressiva" (AGRO-JORNAL, ago. 1976, p. 13). No entanto, afirmava-se, não existia problema quando os venenos eram aplicados "corretamente", ou seja, "TODO AGRICULTOR DEVE utilizar tais defensivos com todas as precauções, dentro dos preceitos técnicos, com toda a segurança individual" (AGRO-JORNAL, ago. 1976, p. 13, grifo do autor). E acrescentava-se:

Não somos contrários a nenhuma medida que retarde o progresso e desenvolvimento da agricultura, desde no entanto, que os instrumentos utilizados não venham por incúria de quem os utiliza, a se transformarem em elemento nefasto à sua saúde (AGRO-JORNAL, ago. 1976, p. 13).
A análise desses fragmentos do jornal, no contexto da época, torna claro que os defensores do uso de venenos na agricultura modernizada simplificaram o problema, já que atribuíram as intoxicações e mortes ao mau uso e culparam os agricultores. Não se pode descartar a desinformação e a imprudência dos aplicadores dos produtos na lavoura como um dos motivos das intoxicações individuais. Existiram títulos e textos no Agro-Jornal que alertaram para os riscos e orientaram para o uso seguro. "Mantenha os inseticidas longe das crianças", recomendavam (COOPERATIVA-JORNAL, jul. 1974, p. 5). Lavar as roupas de trabalho, não percorrer a lavoura depois da aplicação, usar pesticidas menos tóxicos para as abelhas, queimar ou enterrar as embalagens vazias, não usar a boca para desentupir o bico do pulverizador, não comer ou beber durante a aplicação, lavar bem as mãos, braços e rosto antes de comer e beber, usar equipamento de proteção individual, não aplicar os defensivos contra o vento, não lavar os equipamentos de aplicação em rios e lagos, afastar crianças e animais dos locais de aplicação foram algumas das medidas de precaução e segurança sugeridas e publicadas (COOPERATIVA-JORNAL, jan. 1975, p. 15; AGRO-JORNAL, out. 1976, p. 12, 31). A Figura 1 representa a ação educativa do periódico, com orientações ilustradas de segurança. 
Figura 1 - Uso adequado dos defensivos

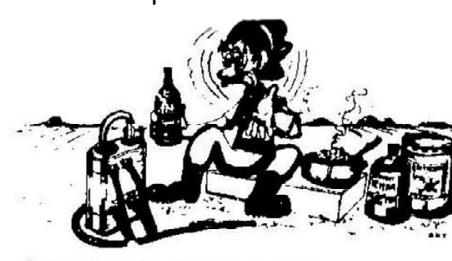

Enquanto estiver lidando com de fensivos, nāo coma, não beba e nào fume. Suas màos e roupas es. taráo contaminadas com o veneno.

Terminada a aplicaçao de defenșivos, as máquinas $e$ utensilio de" ráo ser hem lavados.

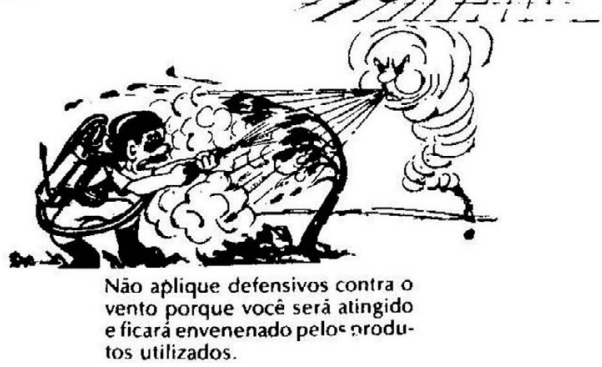

Fonte: Agro-Jornal, out. 1976, p. 31.

Os venenos agrícolas, contudo, não eram neutros, pois, mesmo que todas as prescrições técnicas e medidas de segurança fossem observadas, a contaminação generalizada do ambiente não podia ser evitada. Ela possivelmente implicou em perda de biodiversidade, definida como "a variabilidade de organismos vivos de todas as origens, compreendendo, dentre outros, os ecossistemas terrestres, marinhos e outros ecossistemas aquáticos e os complexos ecológicos de que fazem parte" (CONVENÇÃO SOBRE DIVERSIDADE BIOLÓGICA, 1992). $\mathrm{O}$ aumento da produtividade agrícola, sob o título de desenvolvimento econômico, prevalecia e servia de justificativa para ocultar os problemas socioambientais criados.

\section{Os críticos e as alternativas}

Alguém poderia dizer: na década de 1970, os efeitos nocivos da modernização não eram conhecidos e é anacrônico reprovar, hoje, as opções e práticas da época. Contudo, no contexto de uma grande onda modernizante e da ditadura civil-militar no Brasil, o Agro-Jornal publicou a opinião e os argumentos de alguns críticos e suas propostas alternativas, principalmente ao uso dos venenos. Uma crítica ao desmatamento para abrir novas áreas de cultivo, Um aviso do ecologista ao agricultor e a Campanha do uso adequado de defensivos na bacia do rio Jacuí são títulos de artigos divergentes do geral, publicados no período estudado (COOPERATIVA-JORNAL, fev. 1975; mar. 1975; AGRO-JORNAL, out. 1975).

Destaca-se o artigo Mate a lagarta da soja sem poluir, que propunha o uso do $B a-$ cillus thuringiensis para controlar, biologicamente, o inseto que se reproduzia nas lavouras. O representante comercial da Manah anunciava, na época, o Manapel 320 BT, um inseticida biológico baseado no mesmo bacilo (AGRO-JORNAL, mar. 1975, p. 3; maio 1976).

O Agro-Jornal publicou também, reproduzindo da Folha da Tarde, uma charge de Santiago (Figura 2), que apresentava o monumento conhecido como O laçador, instalado em Porto Alegre, em 1958. Esse ícone estereotipado do homem sul-rio-grandense, foi representado desprovido do laço, conduzindo um trator, portando uma ferramenta e com embalagens vazias de DDT aos seus pés. 
Figura 2 - O gaúcho depois da soja

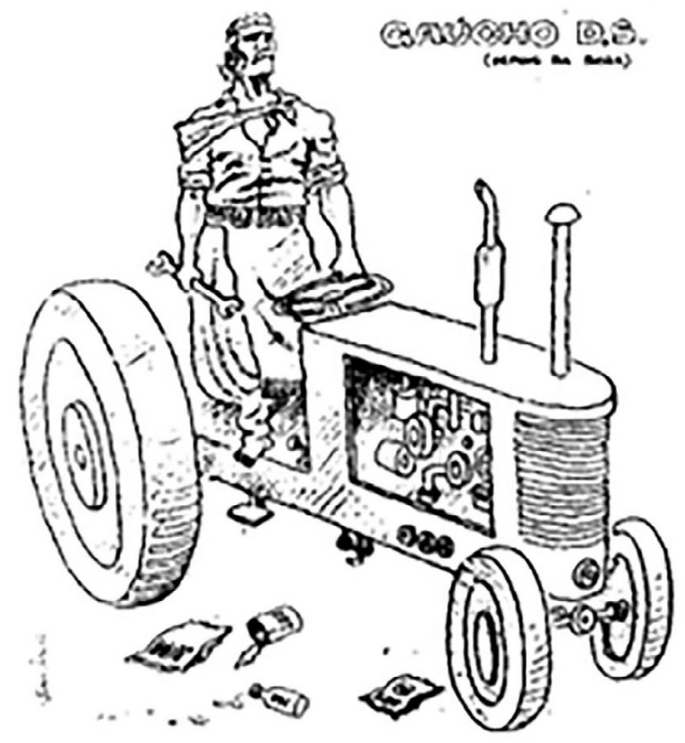

Fonte: Agro-Jornal, set. 1977.

Era uma crítica humorada do artista às profundas mudanças que a modernização da agricultura trouxera e uma evidência de que suas contradições eram percebidas pela sociedade. Os textos e as imagens críticas não predominavam, e as ideias que defendiam não eram hegemônicas, mesmo assim, mostram ao historiador que havia uma postura oposta ao desenvolvimento que desconsiderava os danos socioambientais provocados.

Ainda na década de 1960, Rachel Carson publicou Primavera silenciosa, avaliando e denunciando os danos ambientais causados pelos agrotóxicos, os "elixires da morte", como ela os denominou. Esse livro foi traduzido para o português e publicado no Brasil em 1964. É difícil, contudo, avaliar se, e como, ele influenciou a formação dos engenheiros-agrônomos.

\section{Consideraçoes finais}

A pergunta formulada inicialmente, que motivou e orientou esta pesquisa, tem várias respostas. Mesmo pesquisando um período muito breve (1974-1976) e baseando-se em uma fonte principal, é possível perceber um conjunto de mudanças socioambientais significativas ocorridas em meados da década de 1970. A primeira delas é a introdução - em Passo Fundo e nos municípios próximos - de um pacote tecnológico composto por corretivos, fertilizantes, máquinas, venenos e sementes. $\mathrm{O}$ pacote foi adotado por muitos agricultores com apoio e o incentivo da Ascar, das cooperativas de produção, de alguns bancos, de empresas representantes das indústrias transnacionais e dos técnicos e engenheiros-agrônomos. A modernização ofereceu uma solução para a crise da agricultura colonial policultora, um aumento da produtividade agropecuária e dos ganhos econômicos, mas não explicitou os danos e riscos socioambientais.

A segunda mudança importante corresponde, sob o olhar da história ambiental, a uma aceleração das transformações. Antes do período focado, existiam venenos muito tóxicos, usados para matar formigas e gafanhotos. Um deles era o benzeno hexaclorado, também conhecido como pó de gafanhoto, largamente usado como inseticida a partir da década de 1940. Na década de 1970, contudo, iniciou-se o uso de quantidade e variedade muito maiores de produtos químicos tóxicos na agropecuária. Nos três anos pesquisados, o jornal analisado apresentou diversas inovações tecnológicas - principalmente mecânicas e químicas 
-, exprimindo a velocidade da mudança em curso. Os danos socioambientais desses agrotóxicos nas décadas de modernização, especialmente sobre a fauna silvestre, ainda precisam ser estudados por meio de outras fontes de pesquisa. As críticas formuladas no período, embora importantes, não foram suficientes para promover uma avaliação substancial do processo.

Também foi na década de 1970 que Passo Fundo e outros municípios próximos configuraram-se como uma região produtora de soja ou do binômio trigo-soja, assim como o noroeste do estado do Rio Grande do Sul. Tem-se, assim, a expressão regional da modernização, pensada internacionalmente e valorizada pelo governo civil-militar brasileiro. Novas paisagens foram criadas pela agricultura mecanizada e pelos monocultivos. Pesquisas futuras poderão avaliar o impacto que a modernização e o cultivo da soja, transformado em commodity, teve sobre os remanescentes de florestas nativas, os campos e sobre a agrobiodiversidade regional.

\section{Resumen}

El artículo narra y analiza los principales cambios ambientales provocados por la modernización de la agricultura en el norte del estado de Rio Grande do Sul, Brasil, en un corto período de tiempo, en la década de 1970. Utiliza como fuente de investigación un periódico publicado por la Cooperativa Tritícola Passo Fundo, que represento los intereses y proyectos de otras cooperativas de producción en municipios cercanos. Analiza las peculiaridades locales y regionales de un proceso de modernización que se ha desarrollado en escala nacional e internacional, conocido como la Revolución Verde. Concluye que los cambios fueran intensos y profundos, pero no exentos de críticas y proposición de alternativas.

Palabras clave: Historia rural. Revolución Verde. Passo Fundo.

\section{Abstract}

The article narrates and analyzes the main environmental changes brought by the modernization of agriculture in the north of Rio Grande do Sul, in a short period of time, in the 1970s. The source of research is a newspaper published by Cooperativa Tritícola de Passo Fundo, representing the interests and projects of other nearby municipalities production cooperatives. Analyzes therefore local and regional peculiarities of a process of modernization that has developed a national and international scale, known as the Green Revolution. It concludes that the changes were intense and deep, but not without criticism and alternatives proposition.

Keywords: Rural history. Green Revolution. Passo Fundo.

\section{Referências}

AGRO-JORNAL. Passo Fundo: 1975-1977. Arquivo Histórico Regional. Universidade de Passo Fundo.

ANDRIOLI, Antônio. O fim da picada: plantas transgênicas em expansão na América Latina. In: ANDRIOLI, Antônio; FUCHS, Richard. 
Transgênicos: as sementes do mal. A silenciosa contaminação de solos e alimentos. São Paulo: Expressão Popular, 2008. p. 99-115.

ANVISA. Consulta Pública no 62, de 2001. Disponível em: <http://www4.anvisa.gov.br/ base/visadoc/CP/CP[2853-1-0].PDF>. Acesso em: 12 jan. 2014.

Nota Técnica: reavaliação toxicológica do ingrediente ativo endossulfam. 2009. Disponível em: <http://www4.anvisa.gov. br/base/visadoc/CP/CP\%5B27695-1-0\%5D. PDF>. Acesso em: 14 fev. 2014.

BASF. Basagran 600. 2013. Disponível em: <http://www.agro.basf.com.br/agr/ms/ apbrazil/pt_BR/function/conversions:/publish/content/APBrazil/solutions/herbicides/BULAS/Basagran_600.pdf>. Acesso em: 28 dez. 2015.

BERNARDES, Nilo. Bases geográficas do povoamento do estado do Rio Grande do Sul. Ijuí: Unijuí, 1997.

BRASIL. Decreto $n^{\circ} 4.074$, de 4 de janeiro de 2002. Regulamenta a Lei n. 7.802, de 11 de julho de 1989. Disponível em: <http://www. planalto.gov.br/ccivil_03/decreto/2002/ D4074.htm>. Acesso em: 28 dez. 2015.

Lei $n^{0} 7.802$, de 1989. Dispõe sobre a pesquisa, a experimentação... de agrotóxicos, seus componentes e afins. Disponível em: <www.planalto.gov.br/ccivil_03/leis/L7802. htm>. Acesso em: 28 dez. 2015.

Lei $\mathrm{n}^{\circ}$ 9.974, de 2000. Altera a Lei $\mathrm{n}^{\circ}$ 7.802, de 11 de julho de 1989. Disponível em: <http://www.planalto.gov.br/ccivil_03/ leis/L9974.htm >. Acesso em: 28 dez. 2015.

Lei $\mathrm{n}^{\mathrm{o}} 11.936$, de 14 de maio de 2009. Proíbe a fabricação, a importação, a exportação, a manutenção em estoque, a comercialização e o uso de DDT. Disponível em: <http:// www.planalto.gov.br/ccivil_03/_Ato20072010/2009/Lei/L11936.htm>. Acesso em: 28 dez. 2015.
Ministério da Agricultura, Pecuária e Abastecimento. Ato $\mathrm{n}^{\circ} 40$, de 13 de setembro de 2010. Cancela o registro de produtos à base de endossulfan. Disponível em: <http:// www.agricultura.gov.br/legislacao/atos>. Acesso em: 12 jan. 2016.

BRUM, Argemiro Jacob. Modernização da agricultura: trigo e soja. Ijuí: Fidene, 1985.

CARSON, Rachel. Primavera silenciosa. São Paulo: Melhoramentos, 1964.

CONVENÇÃO SOBRE DIVERSIDADE BIOLÓGICA. 1992. Disponível em: <https:// www.cbd.int/convention/text/>. Acesso em: 9 fev. 2014.

COOPERATIVA-JORNAL. Passo Fundo: 1974-1975. Arquivo Histórico Regional. Universidade de Passo Fundo.

ESPAÑA. Centro Nacional de Referencia sobre Contaminantes Orgánicos Persistentes. Breve perfil de las sustancias COP incluidas en el Convenio de Estocolmo y el Reglamento (CE) no 850/2004. Disponível em: <http://www.cnrcop.es/gc/assets/docs/Lindano.pdf >. Acesso em: 10 jan. 2016.

FEDERAÇÃO BRASILEIRA DE PLANTIO DIRETO E IRRIGAÇÃO. Histórico. [ca. 2013]. Disponível em: <http://febrapdp.org.br/historico $>$. Acesso em: 10 fev. 2016.

FELIZARDO, Julia Netto (Org.). Evolução administrativa do Estado do Rio Grande do Sul. Porto Alegre: FEE, 1981.

GERHARDT, Marcos. História ambiental da erva-mate. Tese (Doutorado em História) - Universidade Federal de Santa Catarina, Florianópolis, 2013.

GERHARDT, Marcos; NEDEL, Rossana P. Uma história ambiental da modernização da agricultura no noroeste do Rio Grande do Sul. In: ANDRIOLI, Antônio Inácio (Org.). Tecnologia e agricultura familiar: uma relação de educação. Ijuí: Unijuí, 2009. p. 77-113. 
GOLIN, Tau. As fronteiras sulinas. In: PICCOLO, Helga I. L.; PADOIN, Maria M. (Dir.). Império. Passo Fundo: Méritos, 2006. p. 491-531. (Coleção História Geral do Rio Grande do Sul, v. 2).

KLANOVICZ, Jó. Corrigir os erros da natureza: húbris, conhecimento agronômico e produção de maçãs no sul do Brasil. Revista Brasileira de História da Ciência, Rio de Janeiro, v. 5, n. 1, p. 131-145, jan./jun. 2012.

LINHARES, Temístocles. História econômica do mate. Rio de Janeiro: José Olympio, 1969.

MACHADO, Ironita P. Entre justiça e lucro: Rio Grande do Sul 1890-1930. Passo Fundo: UPF Editora, 2012.

MAKHTESHIM. Thionex 350 EC. 2010. Disponível em: <http://www2.dupont.com/DuPont_Crop_Protection/pt_BR/assets/downloads/bula/Thionex_bula2.pdf>. Acesso em: 28 dez. 2015.

NORTOX. Trifluralina gold. 2014. Disponível em: <http://www.nortox.com.br/produto/ herbicidas/trifluralina-gold $>$. Acesso em: 28 dez. 2015.

PÁDUA, José Augusto. As bases teóricas da história ambiental. Estudos Avançados, São Paulo, v. 24, n. 68, p. 81-101, 2010.

PONTING, Clive. Uma história verde do mundo. Rio de Janeiro: Civilização Brasileira, 1995.

ROCHE, Jean. A colonização alemã e o Rio Grande do Sul. Tradução de Emery Ruas. Porto Alegre: Globo, 1969.

SYNGENTA. Gramoxone 200. 2015. Disponível em: <http://www3.syngenta.com/country/br/pt/produtosemarcas $>$. Acesso em: 10 jan. 2016.

TEDESCO, João Carlos; NEUMANN, Rosane Marcia (Org.). Colonos, colônias e colonizadoras: aspectos da territorialização agrária no Sul do Brasil. Porto Alegre: Letra \& Vida, 2013. v. 3.
UNITED STATES ENVIRONMENTAL PROTECTION AGENCY. DDT: a brief history and status. [ca. 2015]. Disponível em: <https:// www.epa.gov/ingredients-used-pesticideproducts/ddt-brief-history-and-status>. Acesso em: 13 jan. 2016.

VELOSO, Henrique Pimenta; RANGEL FILHO, Antonio Lourenço Rosa; LIMA, Jorge Carlos Alves. Classificação da vegetação brasileira adaptada a um sistema universal. Rio de Janeiro: IBGE; Departamento de Recursos Naturais e Estudos Ambientais, 1991.

WENTZ, Liliane Irma Mattje. Os caminhos da madeira: região norte do Rio Grande do Sul, 1902-1950. Passo Fundo: UPF Editora, 2004.

WORSTER, Donald. Transformações da terra: para uma perspectiva agroecológica na História. Ambiente $\mathcal{E}$ Sociedade, v. 5, n. 2, ago./dez. 2002; v. 6, n. 1, jan./jul. 2003.

ZARTH, Paulo Afonso. História agrária do planalto gaúcho: 1850-1920. Ijuí: Unijuí, 1997.

Agricultura e impactos ambientais. In: NODARI, Eunice Sueli; KLUG, João (Org.). História ambiental e migrações. São Leopoldo: Oikos, 2012. p. 54-76. 